\title{
Editorial
}




\title{
Acta de Otorrinolaringología \& Cirugía de Cabeza y Cuello
}

www.revistaacorl.org

\section{Editorial invitado}

\section{Cultivando estrategias para mantener el optimismo en tiempos dificiles}

\section{Cultivating strategies to maintain optimism in hard times}

\author{
Ana María Guerra Lozano* \\ * $\quad$ Psiquiatría, Universidad del Valle. Psiquiatra, Fundación Valle del Lili
}

Forma de citar: Guerra-Lozano AM. Cultivando estrategias para mantener el optimismo en tiempos dificiles. Acta otorrinolaringol. cir. cabeza cuello. 2020; 48 (1): 25-28.DOI 10.37076/acorl.v48i1.513

\section{INFORMACIÓN DEL ARTÍCULO}

Historia del artículo:

Recibido: 3 de Mayo de 2020

Evaluado: 13 de Mayo de 2020

Aceptado: 14 de Mayo de 2020

Palabras clave (DeCS):

SARS-CoV-2, infecciones por coronavirus, otorrinolaringología, atención ambulatoria, desinfección, equipo de protección personal.
Para el momento en que escribo y comparto este texto, hemos estado inmersos en la pandemia por SARS-CoV-2 hace varios meses. Habiendo pasado por las primeras semanas de incredulidad, sentirnos ajenos a la situación y angustia progresiva en la fase de preparación, algunos habrán vivido ya la experiencia directa de atender pacientes, sentirse en riesgo físico o estar anticipando un futuro incierto, que de alguna manera se vive como una traición a nuestras expectativas y al esfuerzo dedicado por años para construir una vida acorde a nuestros valores y deseos.

En este proceso, nos vemos afectados no solo por nuestras experiencias del presente y pasado individual, sino por todos los estímulos a que nos vemos sometidos actualmente: las opiniones, mensajes, recomendaciones, predicciones contradictorias, el pesimismo y la angustia en el entorno.

Es tanto un duelo por la vida que ha cambiado, como por la pérdida de la certeza, la confianza, la predictibilidad con la que contábamos hasta ahora.

Y como en todo proceso de duelo, es muy probable que pueda reconocerse pasando por fases de confusión, rabia, ansiedad, frustración, impotencia y negación, alternadas con otras de mayor tranquilidad, optimismo, confianza, aceptación y entrega.

Correspondencia:

Ana María Guerra Lozano

Email: ana-guerra@fvl.org.co

Dirección: Cra 98 \# 18-49, Cali, Colombia

Teléfono: 572-3319090 
Suele ser sorprendente para uno mismo el no poder predecir cómo va a sentirse de un momento a otro, de un día a otro. Pensar que ya había logrado tranquilizarse y encontrarse de nuevo en una sensación intensa de malestar. Esta es la reacción humana del duelo: el proceso progresivo de aceptar la pérdida, que en este caso podría ser tanto de la salud propia o la vida de un ser querido, como de la visión del mundo como lo habíamos conocido, la pérdida de la tranquilidad, del optimismo.

El ajuste saludable, que sería la respuesta ideal, se ve comprometido por la condición cambiante de la situación local, nacional y mundial. Todos necesitamos poder afianzarnos en algo que nos de certeza, pero en este momento, parece que las circunstancias se conjugan para restárnosla.

Como seres humanos, pero en especial como médicos en ejercicio, necesitamos recuperar la tranquilidad. Es sabido que el estrés, si bien inevitable y útil en situaciones de emergencia, no es saludable en el mediano y largo plazo.

El estrés, a través de la activación del sistema nervioso simpático tiene efectos negativos no solo a nivel cardiovascular, sino sobre los procesos de atención, consolidación de la memoria, procesamiento de información, toma de decisiones, estilo de reacción, impulsividad. Nosotros dependemos de la atención al detalle para tomar tanto buenas decisiones clínicas, como para asegurarnos de protegernos adecuadamente. En este contexto, cobran importancia todas las estrategias efectivas que podamos incorporar en nuestra vida cotidiana, para cultivar emociones positivas.

Podría parecer un contrasentido o un pedido irracional el fortalecer emociones positivas en un momento como éste, pero bien vale el esfuerzo si consideramos que mientras las emociones negativas (miedo, rabia, tristeza, culpa, vergüenza) limitan la atención y la memoria, las emociones positivas permiten desarrollar patrones de pensamiento mas flexibles, creativos, integrados y eficientes, al mismo tiempo que reducen el metabolismo basal, presión arterial, frecuencia cardiaca, frecuencia respiratoria y tensión muscular.

Al hablar de emociones positivas, me refiero a aquellas como el optimismo, la alegría, esperanza, amor, perdón, compasión, confianza, capacidad de admiración, gratitud y todas las que involucran conexión con otros.

Así mismo, retomo el hecho de que mucho se ha escrito sobre resiliencia, y en especial en una época como ésta, encontramos la recomendación de ser resilientes o fortalecer la resiliencia como estrategia para superar la dificultad del momento.

\section{Entonces, ¿Qué es resiliencia?}

Una manera de definirla es como la capacidad de responder a la adversidad en forma saludable y productiva. Más que la capacidad de recuperarse de situaciones difíciles ya pasadas, la resiliencia es un estado mental que permite pensar con agudeza, flexibilidad y amplitud (1).

La resiliencia, a su vez, puede pensarse como constituida por unas competencias nucleares:
- Auto conciencia (reconocer los propios pensamientos, emociones, comportamientos)

- Auto regulación (habilidad para regular los impulsos, pensamientos, emociones, comportamientos para lograr sus objetivos)

- Optimismo (reconocer la bondad en uno mismo y en otros, identificar lo que se puede controlar, mantenerse en la realidad)

- Agilidad mental (flexibilidad, agudeza, perspectiva)

- Las fortalezas del carácter

- Conexión (construir relaciones fuertes a través de comunicaciones positivas y efectivas, empatía, disposición para pedir y para ofrecer ayuda)

En este punto, el pedido de cada uno de nosotros sería entonces identificar estrategias, ejercicios fáciles de abordar para fortalecer la resiliencia y las emociones positivas en la vida cotidiana.

Cobran importancia de esta manera, mas que nunca, las estrategias de mindfulness no formal y de psicología positiva, que presentaré de la manera más sencilla y apegada a la definición de los autores, para beneficio de todos aquellos que no estamos entrenados en mindfulness, no tenemos una práctica de meditación constante ni hemos venido haciendo ejercicios orientados a enfocar nuestra atención en los aspectos positivos de la vida.

Porque si bien no tenemos control alguno sobre el futuro, si podemos elegir nuestra manera de interpretar y afrontar las situaciones. Podemos pensar menos en querer que las cosas sean distintas de lo que son, y esforzarnos, con gentileza, paciencia y compasión hacia nosotros mismos, en la aceptación, como punto de partida para la acción inteligente.

¿Por qué mindfulness?

Minfulness, o en su traducción al español Atención Plena, atiende a la riqueza del aquí y el ahora, en contraposición con las creaciones mentales de la ansiedad y la depresión, que nos sitúan en el pasado que no podemos modificar o en un futuro desconocido y sobre el que no tenemos control (2).

$\mathrm{Si}$ entendemos la mente como un proceso que regula el flujo de energía y de información captada del entorno, mindfulness es una manera de hacernos cargo de la dirección y calidad de nuestras vidas, incluyendo nuestras relaciones con la familia, el trabajo, el mundo y muy especialmente, la relación con nosotros mismos. Mindfulness, en su sentido mas general, es un despertar de la vida en automático, hacia experiencias mas sensibles y novedosas en la vida cotidiana (3).

Veamos algunos ejercicios:

\section{Parar:}

El pedido es dejar de Hacer por un momento, para ponerse en modo "Ser". Detener las acciones para preguntarse: ¿Qué está pasando en este momento? ¿Qué estoy sintiendo?, ¿Qué veo? ¿Qué escucho? 
En verdad, tal vez no necesite hacer esa llamada pendiente en este momento, o revisar sus mensajes o moverse, justo ahora. Tal vez pueda darse la oportunidad de detenerse por unos minutos y solo observar dentro de si mismo.

\section{Práctica:}

Detenerse, sentarse, tomar conciencia de su respiración algunas veces, a lo largo del día. Puede ser por unos minutos o en ocasiones tan solo por unos segundos.

No necesita mas que hacer contacto con su respiración; cómo comienza y cómo termina, ese espacio breve de pausa entre la inhalación y la exhalación, dejándose llevar por esa observación, aceptando completamente el momento presente, sea lo que sea que siente o que percibe en ese momento.

Por ese pequeño espacio de tiempo, no intente cambiar nada fuera ni dentro de sí, solo respire. Deje ir el deseo de que las cosas sean diferentes en este momento; en su cuerpo y en su mente, dese el permiso de aceptar que este momento es tal como es.

Luego, cuando le parezca oportuno, retome sus actividades, con atención y resolución.

\section{Asi es:}

Este ejercicio se enfoca en aceptar, en el sentido de notar las cosas o las situaciones tal como son, sin la intención de "mejorarlas" o cambiarlas. Cuando dejamos ir el deseo de que las cosas sean distintas en este momento, tomamos un paso hacia la posibilidad de aceptarlas tal como son, aquí, ahora (3).

\section{Práctica:}

Recuérdese cada tanto "así es". Recuerde que Aceptar lo que está pasando no es lo mismo que Resignarse. Aceptar solo significa el reconocimiento claro de aquello que sucede, de que lo que está pasando, en verdad está pasando. La aceptación no le indica lo que debe hacer, pero su decisión acerca de cómo actuar, cómo proceder o responder, qué hacer, nace de su comprensión profunda de este momento en particular.

\section{Captar el momento:}

La mejor manera de captar el momento es prestar atención, estar despierto y sensible a los detalles. La mente tiene un hábito de escapar del momento presente, pensando en lo que ya sucedió, lo siguiente por hacer, las infinitas posibilidades. Así que este ejercicio consiste en mantener la atención en un objeto por un corto período de tiempo. Se dará cuenta de que para cultivar la atención plena, necesitará recordarse una y otra vez que necesita permanecer despierto... recuérdese mirar, oler, sentir, ser (3).

\section{Práctica:}

Pregúntese en este momento, “¿estoy despierto?, “¿Dónde está mi mente en este momento?"

\section{Prestar atencion a la respiración:}

La respiración es el aliado más a nuestro alcance para fijar la atención, es un ancla al momento presente. Al prestar atención a la respiración, podemos recordarnos que estamos aquí y ahora, de manera que podamos mantenernos completamente presentes con lo que está sucediendo.

Utilice la respiración como un aliado de su atención, simplemente sintonizándose con la sensación de respirar, la sensación del aire que entra y la sensación del aire que sale de su cuerpo. Solo sentir la respiración. Respirar y reconocer que está respirando. No necesita hacer nada distinto de su respiración habitual, ni necesita sentir nada especial, ni pensar en la respiración, solo sentir. Ni siquiera necesita hacerlo por un tiempo largo. Usar la respiración para devolvernos al momento presente no toma tiempo, es solo un cambio de foco de la atención (3).

\section{Práctica:}

Mientras permanece atento a una inhalación y a una exhalación completa, mientras entra y sale el aire, mantenga su mente abierta y libre frente a este momento, solo respire. Abandone todas las ideas de ir a algún otro sitio, obtener otro resultado, lograr que las cosas sean diferentes. Cuando la mente vaga, solo regrese a la respiración una y otra vez, reuniendo momentos de atención, respiración tras respiración. Ensaye a lo largo del día.

La practica continuada y el esfuerzo amable, gentil consigo mismo, le ayudarán a construir una sensación de calma y ecuanimidad. El espíritu del mindfulness es practicar para recibir cada momento como es, bonito o feo, agradable o desagradable, y luego trabajar con lo que es y está, en el momento presente.

\section{Generosidad:}

La generosidad, es un elemento valioso para cultivar la atención plena. Tanto si la vive a través de dar, como si experimenta a través de recibir, o en este caso, darse a si mismo.

Este es un buen punto para comenzar; ver si puede darse a si mismo regalos que sean verdaderas bendiciones, tales como la auto-aceptación, o regalarse momentos del día para si mismo, sin realizar acciones que cumplan un objetivo. No solo darse el regalo, sino desarrollar la sensación profunda de que merece aceptar estos regalos, sin verse obligado a hacer nada a cambio (4).

\section{Práctica:}

Intente conectarse con ese lugar en su interior en donde reside la riqueza, sin limites. Ensaye compartir esa energía, la riqueza de su ser, su mejor versión, su entusiasmo, vitalidad, espíritu, confianza, apertura, su presencia. Comparta esta riqueza consigo mismo, su familia y con las personas a su alrededor.

Esta generosidad no se trata de dar cosas. Por encima de todo, generosidad en este sentido es un regalo interior, un estado, una sensación. 


\section{Tres cosas buenas}

En general, tenemos una tendencia a dedicar mayor atención a aquellas cosas o situaciones que nos generan incomodidad, o frente a las cuales nos gustaría introducir cambios o mejoras. Pero al mismo tiempo que ocurren todas esas cosas "incomodas, malas", están pasando muchas otras situaciones, grandes o pequeñas, que son satisfactorias, buenas o positivas (1).

Este ejercicio se trata de dar relevancia a estos hechos. Requiere constancia. Su beneficio se percibe al mantener la atención sostenida a lo largo de los días.

\section{Práctica:}

Cada día, al terminar la jornada, escriba "Tres cosas buenas que han pasado el día de hoy".

Como mencioné antes, pueden ser cosas grandes o pequeñas, pero deben ser específicas (por ejemplo, "el café de esta mañana estaba delicioso", en lugar de escribir "me gusta el café")

Practique comenzar sus conversaciones con la familia al regresar a casa, o cuando habla con una persona cercana, preguntando por "algo bueno que haya pasado el día de hoy".

Se sorprenderá al principio de que, inmerso como está en muchas preocupaciones y tareas, se le dificulta reconocer cosas buenas en el día, pero poco a poco, se sorprenderá también observando que cada día es mas fácil verlas, recordarlas y registrarlas y la gran satisfacción que le genera este pequeño acto de reconocimiento.

\section{Saborear}

Esta actividad se trata de prestar atención plena a dos actividades a lo largo del día, por un espacio de unos dos o tres minutos cada vez (1).

\section{Práctica}

Escoja cualquier actividad de su vida cotidiana, variando de día en día. Por ejemplo: al momento de comer, deje de lado su celular, computador, el libro que estaba leyendo, incluso la conversación con su familia y concéntrese por dos minutos en la experiencia de comer. Cómo lucen los alimentos en su plato, cuál es su textura, su sabor... cuál le gusta mas, cuál prefiere. $\mathrm{O}$ al lavarse los dientes, note la sensación del agua, el cepillo, la espuma, la sensación de limpieza al terminar.
El destino de este viaje colectivo que no elegimos, no es fijo ni está predeterminado, de manera que al menos por el momento, tenemos la posibilidad de enfocarnos en hacer mejor la experiencia individual de viaje; podemos elegir cómo afrontar la situación: dejarnos llevar pasivamente por los hábitos y las fuerzas que no controlamos, quedando inmersos en pensamientos que nos atemorizan, o podemos engancharnos, en forma activa, en vivir nuestra vida en forma diferente, incluso si las circunstancias por las que atravesamos en este momento no nos gustan. Esta participación activa en nuestras vidas, es la estrategia a nuestro alcance para aliviar el sufrimiento, tanto propio, como de nuestro entorno.

\section{Conflicto de interés}

El autor declara no tener ningún conflicto de interés

\section{BIBLIOGRAFIA}

1. Dilip V. Jeste \& Barton W. Palmer (editors), Positive Psychiatry. A Clinical Handbook. Washington, D.C.: American Psychiatric Publishing, 2015.

2. Siegel, Daniel J. The Mindful Brain: Reflection and Attunement in the Cultivation of Well-Being. New York: W.W. Norton, 2007. Print.

3. Kabat-Zinn, Jon. Wherever You Go, There You Are: Mindfulness Meditation In Everyday Life. New York : Hyperion, 1994

4. Kabat-Zinn, Jon. Coming to Our Senses: Healing Ourselves and the World Through Mindfulness. London: Piatkus, 2005. Print. 